\title{
Complications associated with molding helmet therapy for positional plagiocephaly: a review
}

\author{
William C. Gump, M.D., Ian S. Mutchnick, M.D., M.S., \\ and Thomas M. Moriarty, M.D., Ph.D.
}

Division of Pediatric Neurosurgery, Norton Neuroscience Institute and Kosair Children's Hospital, Louisville, Kentucky

\begin{abstract}
Molding helmet therapy is a widely accepted treatment for positional plagiocephaly that is generally considered to be low risk. Multiple large outcome studies have shown good results, but adverse events are rarely reported. The literature on helmet therapy was reviewed to clarify the clinical experience with associated complications. Although significant complications were extremely rare, there was a large degree of variability in detection of lesser problems such as minor skin irritation. Patients with a primarily brachycephalic morphology may be at higher risk for poorly fitting orthoses. Most reported complications are minor and self-limited. Maintenance of good helmet hygiene appears to be the most effective strategy for reducing or eliminating complications.
\end{abstract} (http://thejns.org/doi/abs/10.3171/2013.5.FOCUS13224)

\section{KEY WORDS • positional plagiocephaly • molding helmet • cranial orthosis • complications}

$\mathrm{T}$ HE prevalence of positional plagiocephaly in infants has grown significantly with the "Back to Sleep" campaign. The incidence of this deformity is estimated to have increased from $0.3 \%$ prior to the campaign to $8.2 \%$ or even higher today, depending on the sensitivity of criteria used to establish the diagnosis. ${ }^{11,13,14,19,33}$ Given this increased prevalence, careful examination of treatment strategies and their potential complications is important.

It has been determined that about $85 \%$ of cranial growth takes place during the 1st year of postnatal life, and treatment paradigms focus primarily on this age group. ${ }^{23}$ Although esthetic improvement is considered the primary basis for treatment, some studies have suggested that uncorrected deformational plagiocephaly is associated with long-term neurological sequelae similar to those seen with untreated craniosynostosis. ${ }^{6,15}$ These problems can include abnormal muscle tone, delays in psychomotor development, and perception of developmental delay by parents.

Common management strategies include active repositioning and molding helmet therapy, with neither option having been shown to be conclusively superior. . $^{2,5,8,10,12,25,31}$ One systematic review found 5 studies that suggested superiority of helmet therapy, although significant potential biases were noted. ${ }^{33}$ At least 1 study found active repositioning to be slightly superior to other options, although it was associated with a longer active management period. ${ }^{21}$

Cranial orthoses are generally perceived to represent a low-risk intervention; the rate of complications associated with their use has been recently estimated at $1 \%$ or less. ${ }^{25}$ Concerns, if cited, commonly include the potential for skin irritation and pressure sores at the sites of maximal applied scalp force. ${ }^{27}$ A physician survey suggested that neurosurgeons were less likely to prescribe molding helmets for plagiocephaly than plastic surgeons. ${ }^{17}$ There exists a spectrum of available orthotic devices. Device-specific case series have reported using noncustomized soft foam helmets, custom-built helmets, or headbands. $1,23,28,29$ The purpose of this study is to review the available literature on complications associated with molding helmet therapy.

\section{Methods}

A PubMed query was performed for English-language articles published between 1990 and April 2013, using the following search terms in various combinations: helmet, cranial orthosis, complications, positional, molding, plagiocephaly, and nonsynostotic. References from all selected papers were further examined for additional suitable studies.

\section{Results and Discussion}

Data from randomized studies on positional plagiocephaly interventions are very limited. One randomized trial suggested the superiority of an active physiotherapy 
program over parental counseling without physiotherapy support. ${ }^{30}$ As noted previously, no prospective randomized trials have compared the use of cranial orthoses to active repositioning therapy. ${ }^{3}$

There is widespread consensus in the literature that complications associated with helmet therapy are low or negligible. ${ }^{16,22,23,25}$ A review article published in 2005 found that no study up to that time had reported any serious complications of helmet therapy. ${ }^{20}$ The review's authors described occasional malodorous perspiration, minor skin irritation, nonreimbursable cost, and social stigma of helmet use as potential problems. A subsequent review, published in 2012, examining 20 studies of molding helmet therapy concluded that no study had indicated that any harm was associated with this intervention. ${ }^{5}$

A large prospective study of 260 patients treated with custom helmets reported a morbidity rate of $0 \%{ }^{4}$ Several studies in which cohorts of patients with positional plagiocephaly were treated with various custom or noncustom orthoses reported no treatment-associated complications, including series of 159 patients, 28 patients, 71 patients, 29 patients, 125 patients, 116 patients, 105 patients, and a 97 patient study that also noted that patients with severe brachycephaly can be difficult to fit in orthoses due to poor helmet purchase on a flattened external occipital protuberance. $8,9,18,23,26,28,29,31$ Guidelines published by the American Academy of Pediatrics in 2003 regarding management of positional deformities described favorable results with molding helmets when used in patients between ages 4 and 12 months, and the guidelines recommended molding helmet use if physical therapy and repositioning did not yield satisfactory results. ${ }^{22}$ Although cost and inadequate outcome data were cited as barriers to more widespread use, no complication concerns were noted.

One direct prospective nonrandomized comparison between helmet and nonhelmet management matched 29 infants in the cranial orthosis arm to 45 infants treated with repositioning alone. ${ }^{21}$ Although no complications were reported in either cohort, the authors speculated that a patient with primarily brachycephalic cranial morphology would achieve less satisfactory results with helmet therapy. The authors listed potential problems that could be associated with helmet use: 1) poor helmet fit; 2) skin injury over pressure points; 3) skin reaction to helmet lining materials; 4) poor fit with severe brachycephaly; and 5) unwanted attention by others directed toward the helmet-wearing child.

Two retrospective studies based on families' responses to questionnaires did reveal a small risk of low-acuity adverse events. One report covering 46 patients undergoing molding helmet therapy included a single case of serious pressure spots and hair loss. The family of another child in this cohort had a self-reported unsatisfactory result, described as insufficient deformity correction. ${ }^{7}$ The other retrospective survey study of families of 28 patients treated with cranial orthoses reported 1 case of contact dermatitis and 2 other cases of parental dissatisfaction with the treatment that led to therapy discontinuance. ${ }^{2}$

Only 1 study has specifically addressed complications associated with cranial orthoses. ${ }^{32}$ A retrospective analysis of 410 patients undergoing helmet therapy for positional plagiocephaly was undertaken specifically to examine the complication rate. The authors found, not surprisingly, a higher rate of complications than had been previously described. Their observed complications included 43 pressure sores, 26 cases of ethanol erythema (their protocol for cleaning the inside of the helmet included ethanol wipes), 5 cases of skin infection, 1 case of bacterial abscess requiring local incision and drainage, 25 cases of poor fitting helmet, and 5 cases of unsatisfactory cosmetic results. In this study, deficient fitting of the helmet did not seem to be significantly more prevalent in children who were primarily brachycephalic (6.3\%) compared with those who were plagiocephalic without brachycephaly $(4.4 \%)$, although pressure sores were twice as common in the brachycephaly group (21.9\% vs $10.9 \%)$. The overall rate of complications was not found to be related to the severity of deformity. Deficient fitting of the helmet and an unsatisfactory result in this and other studies were attributed to noncompliance, severe craniofacial deformity, persistent torticollis, delayed age at onset of treatment, or underlying comorbid clinical syndrome. ${ }^{23,24}$

Outcome studies over the longer term are much fewer in number, and none has reported any persistent or delayed complications. A report on 129 patients treated with helmets showed very good parental satisfaction and no long-term complications noted at ages 3 and 4 years, as did a study of 28 patients followed for 5 years or longer. ${ }^{10,18}$ Another study of 166 helmet-treated patients also reported no complications at $3-5$ years posttreatment. ${ }^{12}$

\section{Conclusions}

Although serious complications are very rare, molding helmet therapy is not an entirely risk-free intervention for positional plagiocephaly. Symptoms of mild transient skin irritation are the most commonly described adverse events. The variability in the reported rates of morbidity among series appears to mostly reflect the sensitivity of criteria used to define complications, although survey studies suggest patients' families may have different perceptions of the incidence and severity of helmet-associated complications than the treating physicians. Most reported complications are very mild and are effectively resolved by discontinuing the helmet therapy. Good hygiene is important. Families should be made aware of the potential for problems and steps that can be taken to prevent them.

\section{Disclosure}

The authors report no conflict of interest concerning the materials or methods used in this study or the findings specified in this paper.

Author contributions to the study and manuscript preparation include the following. Conception and design: Gump. Acquisition of data: Gump. Analysis and interpretation of data: Gump. Drafting the article: Gump. Critically revising the article: all authors. Reviewed submitted version of manuscript: Gump. Approved the final version of the manuscript on behalf of all authors: Gump. Study supervision: Gump.

\section{References}

1. Aliberti F, Pittore L, Ruggiero C, Cinalli G, Maggi G: The 
treatment of the positional plagiocephaly with a new thermoplastic orthotic device. Childs Nerv Syst 18:337-339, 2002

2. Clarren SK: Plagiocephaly and torticollis: etiology, natural history, and helmet treatment. J Pediatr 98:92-95, 1981

3. Cummings C: Positional plagiocephaly. Paediatr Child Health (Oxford) 16:493-496, 2011

4. de Ribaupierre S, Vernet O, Rilliet B, Cavin B, Kalina D, Leyvraz PF: Posterior positional plagiocephaly treated with cranial remodeling orthosis. Swiss Med Wkly 137:368-372, 2007

5. Flannery ABK, Looman WS, Kemper K: Evidence-based care of the child with deformational plagiocephaly, part II: management. J Pediatr Health Care 26:320-331, 2012

6. Fowler EA, Becker DB, Pilgram TK, Noetzel M, Epstein J, Kane AA: Neurologic findings in infants with deformational plagiocephaly. J Child Neurol 23:742-747, 2008

7. Govaert B, Michels A, Colla C, van der Hulst R: Molding therapy of positional plagiocephaly: subjective outcome and quality of life. J Craniofac Surg 19:56-58, 2008

8. Graham JM Jr, Gomez M, Halberg A, Earl DL, Kreutzman JT, Cui J, et al: Management of deformational plagiocephaly: repositioning versus orthotic therapy. J Pediatr 146:258-262, 2005

9. Graham JM Jr, Kreutzman J, Earl D, Halberg A, Samayoa C, Guo X: Deformational brachycephaly in supine-sleeping infants. J Pediatr 146:253-257, 2005

10. Hutchison BL, Hutchison LAD, Thompson JMD, Mitchell EA: Plagiocephaly and brachycephaly in the first two years of life: a prospective cohort study. Pediatrics 114:970-980, 2004

11. Hutchison BL, Stewart AW, Mitchell EA: Deformational plagiocephaly: a follow-up of head shape, parental concern and neurodevelopment at ages 3 and 4 years. Arch Dis Child 96: 85-90, 2011

12. Jalaluddin M, Moss S, Shafron DH: Occipital plagiocephaly: the treatment of choice. Neurosurgery 49:545, 2001 (Abstract)

13. Kalra R, Walker ML: Posterior plagiocephaly. Childs Nerv Syst 28:1389-1393, 2012

14. Kane AA, Mitchell LE, Craven KP, Marsh JL: Observations on a recent increase in plagiocephaly without synostosis. Pediatrics 97:877-885, 1996

15. Kordestani RK, Patel S, Bard DE, Gurwitch R, Panchal J: Neurodevelopmental delays in children with deformational plagiocephaly. Plast Reconstr Surg 117:207-220, 2006

16. Laughlin J, Luerssen TG, Dias MS: Prevention and management of positional skull deformities in infants. Pediatrics 128:1236-1241, 2011

17. Lee A, Van Pelt AE, Kane AA, Pilgram TK, Govier DP, Woo AS, et al: Comparison of perceptions and treatment practices between neurosurgeons and plastic surgeons for infants with deformational plagiocephaly. Clinical article. J Neurosurg Pediatr 5:368-374, 2010

18. Lee RP, Teichgraeber JF, Baumgartner JE, Waller AL, English JD, Lasky RE, et al: Long-term treatment effectiveness of molding helmet therapy in the correction of posterior deformational plagiocephaly: a five-year follow-up. Cleft Palate Craniofac J 45:240-245, 2008

19. Looman WS, Flannery ABK: Evidence-based care of the child with deformational plagiocephaly, Part I: assessment and diagnosis. J Pediatr Health Care 26:242-250, 2012

20. Losee JE, Mason AC: Deformational plagiocephaly: diagnosis, prevention, and treatment. Clin Plast Surg 32:53-64, viii, 2005

21. Loveday BP, de Chalain TB: Active counterpositioning or orthotic device to treat positional plagiocephaly? J Craniofac Surg 12:308-313, 2001

22. Persing J, James H, Swanson J, Kattwinkel J: Prevention and management of positional skull deformities in infants. Pediatrics 112:199-202, 2003

23. Pollack IF, Losken HW, Fasick P: Diagnosis and management of posterior plagiocephaly. Pediatrics 99:180-185, 1997

24. Pomatto JK, Littlefield TR, Manwaring K, Beals SP: Etiology of positional plagiocephaly in triplets and treatment using a dynamic orthotic cranioplasty device. Report of three cases. Neurosurg Focus 2(2):e2, 1997

25. Robinson S, Proctor M: Diagnosis and management of deformational plagiocephaly. A review. J Neurosurg Pediatr 3: 284-295, 2009

26. Shamji MF, Fric-Shamji EC, Merchant P, Vassilyadi M: Cosmetic and cognitive outcomes of positional plagiocephaly treatment. Clin Invest Med 35:E266, 2012

27. Strohecker B: External cranial vault molding helmets. Plast Surg Nurs 16:74-76, 1996

28. Teichgraeber JF, Ault JK, Baumgartner J, Waller A, Messersmith M, Gateño J, et al: Deformational posterior plagiocephaly: diagnosis and treatment. Cleft Palate Craniofac J 39: 582-586, 2002

29. Thompson JT, David LR, Wood B, Argenta A, Simpson J, Argenta LC: Outcome analysis of helmet therapy for positional plagiocephaly using a three-dimensional surface scanning laser. J Craniofac Surg 20:362-365, 2009

30. van Vlimmeren LA, van der Graaf Y, Boere-Boonekamp MM, L'Hoir MP, Helders PJM, Engelbert RHH: Effect of pediatric physical therapy on deformational plagiocephaly in children with positional preference: a randomized controlled trial. Arch Pediatr Adolesc Med 162:712-718, 2008

31. Vles JS, Colla C, Weber JW, Beuls E, Wilmink J, Kingma H: Helmet versus nonhelmet treatment in nonsynostotic positional posterior plagiocephaly. J Craniofac Surg 11:572-574, 2000

32. Wilbrand JF, Wilbrand M, Malik CY, Howaldt HP, Streckbein $\mathrm{P}$, Schaaf H, et al: Complications in helmet therapy. J Craniomaxillofac Surg 40:341-346, 2012

33. Xia JJ, Kennedy KA, Teichgraeber JF, Wu KQ, Baumgartner JB, Gateno J: Nonsurgical treatment of deformational plagiocephaly: a systematic review. Arch Pediatr Adolesc Med 162: 719-727, 2008

Manuscript submitted May 13, 2013.

Accepted May 30, 2013.

Please include this information when citing this paper: DOI: 10.3171/2013.5.FOCUS13224.

Address correspondence to: William C. Gump, M.D., Division of Pediatric Neurosurgery, 210 E. Gray St., Ste. 1102, Louisville, KY 40202. email: william.gump@nortonhealthcare.org. 